\title{
O papel do atleta na sociedade e o controle de dopagem no esporte
}

\author{
Francisco Radler de Aquino Neto ${ }^{1}$
}

\section{RESUMO}

A prática do doping e seu controle são abordados numa perspectiva histórica. As razões para sua prática pelos atletas e a responsabilidade da sociedade sobre esse comportamento são avaliadas. Em seguida, informações sobre a sofisticação atual das práticas de dopagem e a conseqüente evolução das técnicas de análise para seu controle são apresentadas. A situação do seu controle no país, com metodologia do Comitê Olímpico Internacional, é apresentada, bem como a sua complexidade e os custos envolvidos. Esse panorama da situação do controle do doping no Brasil pretende situar os profissionais da medicina desportiva e do desporto em geral nesse segmento importantíssimo para a preservação da integridade física e mental de nossos atletas.

Palavras-chave: Controle de dopagem. Doping. Jogos Olímpicos. Estimulantes. Anabolizantes. Diuréticos. Narcóticos. Analgésicos. Hormônios peptídicos. Betabloqueadores. Drogas sociais.

\section{ABSTRACT}

\section{The athlete's role in society and doping control in sports}

Doping and its control are presented in a historical perspective. The reasons for doping by athletes and the responsibility society has towards this behavior are commented. Information regarding sophisticated doping means and the evolution of the analytical techniques to control them are briefly evaluated. Doping control according to the In-

1. Coordenador do Laboratório de Controle de Dopagem (LAB DOP) do Laboratório de Apoio ao Desenvolvimento Tecnológico (Ladetec) do Instituto de Química (IQ) da Universidade Federal do Rio de Janeiro (UFRJ), Rio de Janeiro, RJ, Brasil.

Recebido em: 8/12/2000.

Aceito em: 25/4/2001.

Endereço para correspondência:

Ilha do Fundão, CT, bloco A, sala 607

21949-900 - Rio de Janeiro, RJ

E-mail: radler@iq.ufrj.br ternational Olympic Committee, as performed in Brazil, is acknowledged, as well as its complexity and costs. This scenario regarding doping control in Brazil is intended to serve as background knowledge to sports physicians and professionals dealing with this issue to preserve the physical and mental integrity of our athletes.

Key words: Doping control. Olympic Games. Stimulants. Anabolic agents. Diuretics. Narcotics. Analgesics. Peptide hormones. Beta-blockers. Street drugs.

\section{HISTÓRICO}

Numa perspectiva histórica fica demonstrado que as injunções socioeconômicas levam os atletas a exceder seus próprios limites. No afã da superação, não medem esforços, empregando todos os meios disponíveis. Muitos desses artifícios representam grave risco ao atleta, seus companheiros de equipe, ou adversários. Esse comportamento é diretamente incentivado por dirigentes inescrupulosos, empresários gananciosos, treinadores irresponsáveis, médicos do esporte venais e "amigos" e familiares nem sempre fiéis. Além disso, foi institucionalizado durante a guerra-fria, em especial nos países de regime autocrático (exURSS, ex-RDA). A grande incidência de casos de doping em atletas da China continental lança suspeitas de que essa ainda é uma prática corrente naquela sociedade.

Como se isso não bastasse, o tânatos presente no comportamento social tende a transformar o espetáculo esportivo em algo mais parecido com os "circos romanos".

O esporte na sociedade ocidental passou a fazer parte do tecido social, estando presente em todas as faixas etárias, camadas sociais e representando, em muitos casos, a chan$c e$ de ascensão social e econômica para os menos favorecidos.

É função, portanto, do Estado democrático velar pelo controle de dopagem e de práticas antiéticas no esporte.

Não cabe apelar para o "livre arbítrio" para justificar a prática de doping. A pressão familiar, social e econômica sobre o atleta (isso sem contar com a inconstância e força da mídia) o transforma em um instrumento da vontade alheia, retirando sua capacidade de discernir onde se si- 
tuam os limites éticos, morais e de segurança de seu comportamento.

Nada disso é novo. Em 800 a.C. os gregos incorporaram o esporte ao seu modo de vida em igualdade com as atividades culturais e religiosas. Os eventos esportivos envolviam, sob a égide dos deuses, a participação artística dos atletas, além da parte atlética voltada para a preparação de guerreiros. Mas já se delineava o uso dos jogos como forma de estabelecer a importância geográfica, política e econômica das regiões participantes.

A "profissionalização" do esporte ocorreu a partir de 400 a.C., com prêmios elevados para os vencedores, resultando numa "casta" de desportistas muito bem pagos e prestigiados ${ }^{1}$. Tomando por base relatos de Platão, pode-se atualizar esses valores para algo em torno de U\$ 500.000,00 (500 mil dólares norte-americanos) para vencedores, além de moradia, alimentação, isenção de impostos e do serviço militar. Valores de tal monta levaram à profissionalização do esporte, resultando em sua comercialização, com a conseqüente corrupção do sistema. Os primeiros casos de dopagem são conhecidos: uso da estricnina (um veneno de triste memória) em doses adequadas (?!) usado como estimulante e cogumelos alucinógenos para reforçar a psique antes dos jogos.

O período romano continuou a elevar o prestígio do esporte, mas elevou também sua violência. "Esportes" prediletos passaram a ser lutas de gladiadores e corridas de bigas. Com o conseqüente doping de cavalos para correrem mais e de gladiadores para aumentar a violência dos combates.

A era cristã rejeitou os jogos violentos com o imperador Teodosius proibindo os jogos "pagãos" em 396 d.C. A tentativa de substituí-los por boxe e luta não vingou e a perda de popularidade encerrou a fase de prestígio do esporte.

Somente no século XIX o esporte ressurgiu, curiosamente, na Inglaterra rural, com atividades decorrentes desse estilo de vida ${ }^{1}$. O entretenimento nas celebrações comunitárias envolvia beber, dançar, corridas de sacos e para agarrar porcos, briga de galos e boxe, além de jogos de futebol envolvendo mais de 1.000 jogadores! A industrialização levando à urbanização trouxe uma mudança radical nessas atividades. O esporte teve que se organizar para atuar em espaços confinados, com número reduzido de jogadores e com restrições de tempo e horários decorrentes da rotina do trabalho industrial e urbano. Por outro lado, o desenvolvimento tecnológico da revolução industrial resultou em esportes com "instrumentos" (tênis, golfe, críquete), no horário noturno (luz elétrica) e reacendeu a competição com conotações políticas e socioeconômicas (revolução das comunicações e transporte). Novamente, o profissionalismo e comercialização tomaram conta do esporte, reviven- do o esporte de massa. Ressurge assim toda a pressão sobre os atletas e seu rendimento, o que leva novamente à dopagem (quadro 1). O primeiro caso fatal de que se tem notícia ocorreu em 1886 com um ciclista francês. No ciclismo usavam-se intensivamente as speed balls, mistura de cocaína com heroína!

Na virada do século XX o esporte já assume relevância similar à da época greco-romana. $\mathrm{O}$ esforço de guerra fa-

\section{QUADRO 1}

O lado negro da química empregada no doping ${ }^{1,20}$

\begin{tabular}{|c|c|}
\hline $\begin{array}{l}\text { Ano ou } \\
\text { período }\end{array}$ & Atividade \\
\hline 1886 & $\begin{array}{l}\text { “Tour de France" de ciclismo, Linton morre sob } \\
\text { efeito de estresse e speed ball (cocaína + heroí- } \\
\text { na) }\end{array}$ \\
\hline 1904 & $\begin{array}{l}\text { Primeiro "susto" nas olimpíadas modernas. } \\
\text { Thomas Hicks, maratonista, quase morre devi- } \\
\text { do à mistura de brandy e estricnina. O mais in- } \\
\text { crível é que ele ficou com a "medalha de ouro", } \\
\text { que foi tirada do vencedor quando se descobriu } \\
\text { que este havia feito o percurso de carona num } \\
\text { caminhão! }\end{array}$ \\
\hline Anos 30 & Síntese das anfetaminas substitui a estricnina \\
\hline 1952 & $\begin{array}{l}\text { Nos Jogos de Inverno de Helsinki competido- } \\
\text { res de corrida sobre patins passaram mal devi- } \\
\text { do ao uso de anfetaminas }\end{array}$ \\
\hline 1953 & Anabolizantes sintéticos entram no mercado \\
\hline 1956 & $\begin{array}{l}\text { Abuso de drogas flagrante nas Olimpíadas de } \\
\text { Melbourne }\end{array}$ \\
\hline 1960 & $\begin{array}{l}\text { Kurt Jensen, ciclista dinamarquês, morre por } \\
\text { overdose de anfetamina nas Olimpíadas de } \\
\text { Roma }\end{array}$ \\
\hline 1964 & $\begin{array}{l}\text { Olimpíadas de Tóquio apresentaram atletas com } \\
\text { musculatura surpreendente, lançando a suspei- } \\
\text { ta de abuso de anabolizantes }\end{array}$ \\
\hline 1967 & $\begin{array}{l}\text { Morre Tommy Simpson na "Tour de France" de } \\
\text { ciclismo, devido a estresse e anfetaminas }\end{array}$ \\
\hline 1976 & $\begin{array}{l}\text { Nadadoras alemãs nitidamente "fabricadas" por } \\
\text { doping, nas Olimpíadas de Montreal }\end{array}$ \\
\hline 1980 & Novamente as nadadoras alemãs se destacaram \\
\hline 1988 & $\begin{array}{l}\text { Ben Johnson é flagrado pelo uso de estanozo- } \\
\text { lol, um anabolizante sintético de última geração. } \\
\text { Florence Griffith-Joyner, nitidamente moldada } \\
\text { por anabolizantes, não é flagrada }\end{array}$ \\
\hline
\end{tabular}

Anos 90 Internet banaliza o acesso a, e uso de, anabolizantes e "complementos nutricionais" 
vorece a disseminação do abuso de drogas em diversos países ${ }^{2}$. Mas já nos anos 20, tecido de testículos de macaco era enxertado em atletas, em conseqüência da "organoterapia" que precedeu o advento da endocrinologia moder$\mathrm{na}^{3}$. $\mathrm{O}$ auge desses ensaios folclóricos baseados no conhecimento limitado de como os hormônios são absorvidos e agem no organismo foi o consumo difundido de urina de mulheres grávidas como fonte de anabolizantes, no final da década de 80 . Na década de 40 , o uso de testosterona era corrente e, em 1953, foi produzido o primeiro esteróide sintético que apresentou potência cinco vezes maior do que a testosterona. Com a queda dos regimes comunistas e liberação dos seus arquivos, fica evidente a experimentação, com anabolizantes, para a dopagem oficial de atletas, resultando em vários óbitos registrados ${ }^{4}$.

Outra via de dopagem decorreu do uso por atletas de estimulantes e drogas contra a fadiga, desenvolvidos para o Exército soviético. Essas drogas "vazaram" para o meio desportivo, como foi o caso do bromantano nas Olimpíadas de Atlanta, em 1996. Uma substância desconhecida caracterizada em nove atletas do ex-bloco comunista necessitou de uma articulação internacional no melhor estilo da espionagem da época da guerra-fria para chegar à identificação da droga e, principalmente, aos objetivos de seu uso. Pois, obviamente, tratava-se de droga não descrita nos compêndios médicos e farmacêuticos! Da mesma forma, durante vários meses em 1997, uma nova droga aparece na urina de vários atletas, depois identificada como o carfedon, de propriedades psicoestimulantes e antiestresse.

O abuso exagerado de estimulantes na década de 60, com a disponibilidade das anfetaminas sintéticas, sintetizadas durante a Segunda Grande Guerra, levou ao estabelecimento, pelo Comitê Olímpico Internacional (COI), do controle de dopagem em 1967. Essa prática desenvolveu-se aceleradamente na década de 70. Nas Olimpíadas de Montreal, em 1976, o abuso de anabolizantes ainda não era adequadamente controlado devido à falta de metodologia analítica para detectá-los. Novas técnicas de análise como a cromatografia gasosa acoplada à espectrometria de massas foram desenvolvidas e demonstraram seu potencial para diagnosticar esse abuso 5 . Muito deve ser creditado ao Dr. Manfred Donike, da Escola de Educação Física de Colônia, na Alemanha. Durante anos ele liderou uma cruzada para a caracterização química do abuso de drogas no esporte, lançando as bases científicas e organizacionais para a rede moderna de laboratórios credenciados pelo COI (25 laboratórios em 25 países).

O controle oficial pelo COI começou nos Jogos Olímpicos de Inverno de Grenoble, França, em 1968, mas apenas alguns estimulantes e narcóticos podiam ser testados devido às limitações na metodologia analítica ${ }^{4}$. Em 1976 (Olim-
QUADRO 2

Etapas da luta contra o abuso de drogas no esporte ${ }^{1,2,5,7,21-23}$

\begin{tabular}{|c|c|}
\hline $\begin{array}{l}\text { Ano ou } \\
\text { período }\end{array}$ & Evento \\
\hline 1952 & $\begin{array}{l}\text { Olimpíadas de Helsinki; abuso de drogas carac- } \\
\text { terizado, mas não coibido }\end{array}$ \\
\hline 1956 & $\begin{array}{l}\text { Olimpíadas de Melbourne; abuso de drogas ca- } \\
\text { racterizado, mas não coibido }\end{array}$ \\
\hline 1960 & $\begin{array}{l}\text { Conselho da Europa reunindo } 22 \text { nações elabo- } \\
\text { ra resolução contra o uso de agentes dopantes } \\
\text { no esporte }\end{array}$ \\
\hline 1963 & França aprova legislação anti-doping \\
\hline 1965 & Bélgica segue os passos da França \\
\hline 1967 & $\begin{array}{l}\text { Morre, devido ao abuso de anfetaminas, sendo } \\
\text { televisionado, o ciclista Tommy Simpson, na } \\
\text { Volta da França, obrigando o COI a tomar medi- } \\
\text { das enérgicas }\end{array}$ \\
\hline 1967 & O COI estabelece sua Comissão Médica \\
\hline 1968 & $\begin{array}{l}\text { Primeiro controle de dopagem nas Olimpíadas } \\
\text { de Inverno de Grenoble }\end{array}$ \\
\hline 1968 & $\begin{array}{l}\text { Primeiro controle de dopagem nas Olimpíadas } \\
\text { do México }\end{array}$ \\
\hline 1972 & $\begin{array}{l}\text { Primeira testagem abrangente, introduzindo a } \\
\text { CG como metodologia para triagem de estimu- } \\
\text { lantes e opióides, nas Olimpíadas de Munique }\end{array}$ \\
\hline 1976 & $\begin{array}{l}\text { Primeira testagem para esteróides anabolizan- } \\
\text { tes, empregando radioimunoensaio (RIA), reali- } \\
\text { zada para } 15 \% \text { das amostras das Olimpíadas de } \\
\text { Montreal }\end{array}$ \\
\hline 1983 & $\begin{array}{l}\text { Nova tecnologia de controle de dopagem por } \\
\text { CG-EM provoca êxodo de atletas do Pan-Ame- } \\
\text { ricano de Caracas }\end{array}$ \\
\hline 1984 & $\begin{array}{l}\text { Olimpíadas de Los Angeles contam com con- } \\
\text { junto impressionante de tecnologia, equipamen- } \\
\text { to e especialistas, fruto da associação da Uni- } \\
\text { versidade da Califórnia e a Hewlett-Packard, fa- } \\
\text { bricante de instrumentos científicos e computa- } \\
\text { dores. Primeira testagem dos esteróides anabo- } \\
\text { lizantes com CG-EM, realizada para todas as } \\
\text { amostras. A razão testosterona para epitestos- } \\
\text { terona (critério para abuso de testosterona) foi } \\
\text { realizada pela primeira vez, empregando CG-EM }\end{array}$ \\
\hline 2000 & $\begin{array}{l}\text { Primeira testagem de eritropoetina (EPO), dis- } \\
\text { tinguindo por eletroforese a EPO endógena da } \\
\text { exógena (obtida por técnica recombinante), nas } \\
\text { Olimpíadas de Sydney }\end{array}$ \\
\hline 2000 & $\begin{array}{l}\text { Criação da agência internacional de controle de } \\
\text { drogas (WADA) }\end{array}$ \\
\hline
\end{tabular}


píadas de Montreal), $15 \%$ das amostras controladas foram testadas para anabolizantes; 50\% nas Olimpíadas de Moscou, em 1980, e todas nas de Los Angeles, em 1984, quando técnica, tecnologia, instrumentação e pessoal especializado foram reunidos pela primeira vez num esforço articulado para implementar o exame de anabolizantes como rotina $^{6}$. Na virada do século XXI, o controle de dopagem no esporte assume sofisticação ímpar e engloba, também, drogas sociais. São banidos em várias modalidades desportivas a cocaína e alucinógenos derivados de anfetaminas (sempre proibidos pelo COI) e, de modo inovador, o metabólito característico do consumo de Cannabis sativa (maconha) ${ }^{7}$.

A sofisticação da dopagem acompanha a evolução da farmacologia. Novas drogas com finalidade terapêutica explícita cada vez mais passam a ser prontamente usadas pelos seus efeitos terapêuticos e colaterais. Abusa-se, assim, de beta-agonistas, os conhecidos antiasmáticos (clembuterol, salbutamol, terbutalina) pelo seu efeito colateral anabolizante. Da mesma forma, são empregados insulina e seus análogos, hormônios de crescimento e gonadotrofina coriônica humana!

O transporte de oxigênio para os músculos é essencial para o seu funcionamento e, portanto, motivo de dopagem. A manipulação do sangue para aumentar a taxa de transporte de oxigênio é efetuada com drogas (EPO - eritropoetina, um hormônio peptídico que age na medula e aumenta a produção de glóbulos vermelhos) e pela adição de sucedâneos de sangue, transfusão de sangue e autotransfusão de sangue.

Os grupos de substâncias proibidas pelo COI estão apresentados nos quadros 3 a $5^{8-13}$.

\begin{tabular}{l} 
QUADRO 3 \\
$\begin{array}{l}\text { Classes de substâncias proibidas pelo Comitê Olímpico } \\
\text { Internacional (COI; circular de 21/12/2000 com } \\
\text { lista de substâncias proibidas para 2001)11,24,25 }\end{array}$ \\
\hline Estimulantes \\
Narcóticos e analgésicos \\
Anabolizantes \\
Esteróides \\
Beta-agonistas \\
Diuréticos \\
Betabloqueadores \\
Hormônios peptídicos, miméticos e análogos \\
Gonadotrofina coriônica humana (hCG) (“anabolizante”) \\
Hormônio luteinizante (LH) (“anabolizante") \\
Hormônio de crescimento (hGH) ("anabolizante”) \\
Insulina e análogos (IGF-1) (“anabolizante”) \\
Eritropoetina (oxigenação) \\
\hline
\end{tabular}

Rev Bras Med Esporte - Vol. 7, № 4 - J ul/ A go, 2001
Um pouco caricatos, quem sabe contendo fatores de risco, com algum fundamento científico, mas sem comprovação, são os vários "achismos" do aumento do desempenho.

Os mais atuais são:

a) Roupas especiais para esportes aquáticos. Para ser efetivas, são "engenheiradas" para o corpo do atleta e, portanto, deveriam ser refeitas a cada nova competição.

b) Treinamento em altitude, com repouso em altitudes menores, ou a "maravilha" tecnológica das câmaras hipóxicas. Não foram testados os reais efeitos e problemas colaterais dessa vida em privação de oxigênio.

c) Administração de doses "cavalares" 14 de complementos alimentares sem avaliação científica, sobrecarregando o sistema de eliminação do organismo (rins e fígado), além de perturbações não previsíveis no funcionamento do organismo como um todo e suas vias metabólicas ${ }^{15}$.

d) Uso não abusivo, mas não indicado, de "qualquer coisa" que tenha alguma propriedade que possa ser interessante do ponto de vista de reduzir fadiga, dor ou estresse; aumentar estado de alerta, reflexos e combatividade; ter propriedades anabolizantes, influir na produção de espécies anabolizantes endógenas, servir de matéria-prima para síntese endógena de proteína: por exemplo, adrenalina, ál-

QUADRO 4
Métodos proibidos pelo Comitê
Olímpico Internacional (COI) ${ }^{11,24,25}$


cool, cafeína (abaixo do limite do COI), piconalato de cromo, hormônios tiroidianos, oxigênio (excesso ou redução), glicogênio, aspirina (ácido acetilsalicílico), ácido gamahidroxibutírico (GBH), benzodiazepínicos, corticosteróides, antiinflamatórios (pelo efeito analgésico), broncodilatadores, aminoácidos, creatina, precursores do metabolismo de esteróides anabolizantes... ${ }^{15}$

\section{DESIGNAÇÕES DE MOLÉCULAS COM POSSÍVEL ATIVIDADE BIOLÓGICA; DROGAS E FÁRMACOS}

É preciso enfatizar que, no presente contexto, o termo droga se estende a qualquer fármaco que seja empregado de modo não terapêutico pelo atleta. Como a administração não resulta de indicação terapêutica, diz-se que houve abuso (no consumo) da droga. Muitas dessas práticas não terapêuticas são permitidas, de modo que há abuso de drogas que não é considerado doping. Esse talvez seja o maior desafio dos legisladores da área: como definir quais fármacos banir?

Há outros termos usados para designar moléculas presentes nos seres vivos ou a eles administradas. Do ponto de vista de um emprego que busque benefícios terapêuticos, as substâncias podem ser chamadas de medicamentos, remédios, fármacos e mesmo drogas (em que não há a conotação pejorativa). Por outro lado, se fazem mal ao organismo, são chamadas de venenos, drogas, substâncias tóxicas. Mais recentemente, há a tendência de associar o termo droga às substâncias psicoativas consumidas "socialmente", as ditas "drogas sociais" (maconha, cocaína, heroína, anfetaminas e um sem-número de moléculas e suas denominações e modismos que minam a sociedade contemporânea). Essas são proibidas pela sociedade. Há um terceiro grupo, em geral formado por alucinógenos, em-

QUADRO 6
Efeitos desejados (esporte) e colaterais
do abuso de estimulantes ${ }^{2}$

pregado em rituais religiosos e que também tem sido chamado de droga, cujo uso é permitido de maneira "controlada" pelas comunidades religiosas correspondentes.

Um dos grandes problemas sociais da atualidade é a dependência ou adicção às drogas, fenômeno ligado às drogas explicitamente psicoativas, mas que se verifica, também, no abuso de anabolizantes.

\section{EFEITOS COLATERAIS MALÉFICOS PREVISÍVEIS DO ABUSO DE DROGAS NO ESPORTE}

O desenvolvimento de fármacos envolve a avaliação de seus efeitos colaterais e, quando possível, as consequiências de interações medicamentosas. É óbvio que o que é relatado resulta das pesquisas efetuadas, que são programadas baseadas na experiência dos pesquisadores e custos envolvidos. Assim, mesmo os efeitos colaterais estabelecidos não representam a totalidade do risco envolvido no consumo do fármaco em questão. Apesar disso, os quadros 5 a 16 apresentam alguns riscos conhecidos do uso de drogas comumente empregadas na dopagem esportiva.

\section{QUADRO 7}

Efeitos desejados (esporte) e colaterais do abuso de analgésicos narcóticos ${ }^{2}$

Efeitos desejados para elevar o desempenho esportivo Alívio nas dores moderadas e intensas

Efeitos colaterais fisiológicos

Depressão respiratória

Dependência física e mental grave

Efeitos colaterais mecânicos

Atleta sem dor pode destruir musculatura e articulações

QUADRO 8
Efeitos desejados (esporte) e colaterais
do abuso de betabloqueadores ${ }^{2}$

Efeitos desejados para elevar o desempenho esportivo* Redução de taquicardia e tremor nas mãos por estresse Ganho de precisão por desaceleração dos batimentos cardíacos

Efeitos colaterais

Broncoespasmo em asmáticos

Contra-indicados no caso de insuficiência cardíaca

* Esportes de precisão, tais como, arco e flecha, tiro ao alvo, saltos de esqui, nado sincronizado, sinuca. Benzodiazepínicos também são usados, mas ainda não controlados. 


\section{EFEITOS COLATERAIS MALÉFICOS IMPREVISÍVEIS PARA O ABUSO DE DROGAS NO ESPORTE}

É extremamente importante alertar os atletas e a população em geral sobre os efeitos maléficos do abuso de drogas. Todo medicamento de uso controlado deve esse controle aos riscos inerentes ao seu uso terapêutico. O que

\section{QUADRO 9 \\ Efeitos desejados (esporte) e colaterais do abuso de beta-agonistas ${ }^{26}$}

Efeitos desejados para elevar o desempenho esportivo Estimulante (dosagens maiores que as terapêuticas) Anabolizante (necessárias dosagens muito elevadas)

Efeitos colaterais

Tremores musculares; diminuição da pressão sanguínea, com conseqüente taquicardia e palpitações; vasodilatação pulmonar; nervosismo; acidose lática; hiperglicemia; insônia; vertigens; sudorese; cefaléia; náuseas; vômitos; ansiedade; câimbras musculares; hipopotassemia; hipomagnesemia

Indivíduos portadores de doenças cardiovasculares: além da taquicardia e arritmia cardíaca, provocam dor anginal, palpitações e parada cardíaca

Indivíduos portadores de diabetes: complicações decorrentes da hiperglicemia

\section{QUADRO 10 \\ Efeitos desejados (esporte) e colaterais do abuso de anabolizantes ${ }^{27}$}

Efeitos desejados para elevar o desempenho esportivo Aumento da massa muscular Aumento da agressividade

Efeitos colaterais leves

Virilizantes, femininizantes e tóxicos

Distúrbios do crescimento e desenvolvimento ósseo

Diminuição do HDL e aumento do LDL, favorecendo atenogênese

Homens:

Azoospermia, diminuição dos testículos, impotência; ginecomastia; estreitamento de uretra

Mulheres:

Excessiva pilosidade corporal, calvície de padrão masculino, hipertofia do clitóris, irregularidade ou ausência do ciclo menstrual, voz rouca e acne

Efeitos colaterais graves

Cardiovascular: cardiopatia, infarto agudo do miocárdio, acidente vascular cerebral, embolia pulmonar

Fígado: icterícia, adenoma e carcinoma

Próstata: complicações na próstata e carcinoma

Psicológico: aumento da agressividade; psicose; disforia; depressão

\section{QUADRO 11}

Efeitos desejados (esporte) e colaterais do abuso de hCG ${ }^{28}$

Efeitos desejados para elevar o desempenho esportivo Produção de testosterona

Prevenção da atrofia testicular

Efeitos colaterais

Desconhecidos

\section{QUADRO 12}

Efeitos desejados (esporte) e colaterais do abuso de eritropoetina ${ }^{29,} 30$

Efeitos desejados para elevar o desempenho esportivo Hematopoese, isto é, estímulo à produção de glóbulos vermelhos

Efeitos colaterais

Desencadeamento ou agravamento de hipertensão Supõe-se que o aumento da viscosidade do sangue decorrente da maior produção de glóbulos vermelhos possa levar a problemas cardiovasculares

\section{QUADRO 13}

Efeitos desejados (esporte) e colaterais do abuso de hormônio de crescimento (hGH) ${ }^{31}$

Efeitos desejados para elevar o desempenho esportivo Aumento de massa muscular (evidências conflitantes) Redução de tecido adiposo e aumento de tecido conectivo

Efeitos colaterais de uso continuado

Acromegalia (com sintomas levando mais de dez anos para surgir):

Redução da força muscular

Aumento da massa cardíaca

Cardiopatias graves

Aceleração de osteoartrite

Tumores malignos, particularmente no cólon

Apnéia do sono

Hipertensão

Diabetes melito

\section{QUADRO 14 \\ Efeitos desejados (esporte)* e colaterais do abuso de diuréticos ${ }^{2,32}$}

Efeitos desejados para elevar o desempenho esportivo Redução de peso em esportes em categorias por peso Redução de peso para ginastas

Efeitos colaterais Indefinidos (embora a perda de sais possa ser correlacionada a possíveis problemas cardíacos)

* Também empregados para diluir a urina ou inibir a excreção de drogas e, assim, dificultar a caracterização de outras drogas que estejam sendo eliminadas. 
dizer, então, do seu abuso com finalidades não terapêuticas? Mesmo medicamentos "inócuos" nas dosagens recomendadas podem provocar reações adversas quando tomados em doses excessivas ou por períodos prolongados. O grande risco que se corre é de imaginar que a margem de segurança de uso de determinado fármaco se estende para sua administração em condições de abuso. Obviamente, isso é falso, pois no desenvolvimento e testes clínicos de fármacos não se avaliam os efeitos colaterais da sobredosagem. Outro aspecto relevante é a prática de abuso de várias drogas simultaneamente, mesmo que apenas de vitaminas e complementos alimentares, não tendo sido determinado o seu possível sinergismo (esperado pelos consumidores para seus efeitos benéficos), com conseqüentes efeitos colaterais maléficos.

\section{CARACTERIZAÇÃO DO ABUSO DE DROGAS ${ }^{16}$}

O diagnóstico do abuso de drogas no esporte depende de sua identificação inquestionável em material colhido do atleta. Hoje, devido à facilidade de coleta, garantia de evitar a adulteração e por se tratar de repositório de todas as

\section{QUADRO 15 \\ Efeitos desejados (esporte)* e colaterais do abuso de inibidores de excreção ${ }^{2}$}

Efeitos desejados para elevar o desempenho esportivo Reduzir excreção de drogas para aumentar sua permanência e eficácia de ação no organismo

Efeitos colaterais

Desconhecidos * Também empregados para dificultar a caracterização de outras drogas, ao impedir
sua eliminação pela urina. Mais utilizados: probenecida, sulfinpirazona e inibidores
de carboxianidrase (p.ex., acetazolamida). Alguns diuréticos também atuam dessa
forma (quadro 14).

\begin{tabular}{c} 
QUADRO 16 \\
$\begin{array}{c}\text { Efeitos desejados (esporte) e colaterais } \\
\text { do abuso de corticóides }\end{array}$ \\
\hline Efeitos desejados para elevar o desempenho esportivo \\
Combate à fadiga \\
Ação psicoestimulante \\
Ação antiinflamatória \\
Tolerância à dor \\
Efeitos colaterais \\
Fragilidade dos tendões \\
Rompimentos musculares \\
Fadiga crônica com queda de rendimento \\
Infecções locais e generalizadas \\
Problemas cardiovasculares podem levar à morte \\
\hline
\end{tabular}

moléculas que são eliminadas pelo organismo, considerase a urina como o melhor material para essa finalidade. Cabelo, sangue, saliva ou outros fluidos, excretas e tecidos biológicos apresentam limitações que necessitam ser contornadas para que possam ser de utilidade ${ }^{17}$.

A urina contém moléculas representativas de todas as substâncias presentes no organismo, sejam elas endógenas ou exógenas. Muitas vezes, a excreção da substância de interesse ocorre após modificação. As modificações mais comuns são a funcionalização ou a conjugação, ambas resultantes da necessidade de tornar as moléculas mais polares para que sejam mais solúveis em água (o "solvente" da urina).

A funcionalização, processo metabólico, produz os metabólitos das drogas de interesse. Esses metabólitos, desde que demonstrada sua origem a partir das drogas de interesse, podem ser usados como diagnóstico do abuso das mesmas.

Para simplificar o processo de caracterização, geralmente, decompõem-se os conjugados por hidrólise enzimática, gerando a estrutura não conjugada (droga original ou seu metabólito). Em seguida, é preciso isolar as moléculas de interesse (analitos) dos interferentes e da matriz. Interferentes são moléculas que influem diretamente na caracterização dos analitos, prejudicando sua observação ou identificação. A matriz representa todos os demais componentes da amostra que, devido à sua presença, diluem os analitos ou perturbam os processos envolvidos na sua análise, também prejudicando sua observação ou identificação.

Os procedimentos de isolamento envolvem várias etapas de purificação da fração que contém os analitos, bem como a concentração desses. Isso aumenta a capacidade de observação da presença dos analitos ${ }^{18}$ (chamada de sensibilidade de detecção). Quanto maior a sensibilidade de detecção, menor a quantidade de analito que se pode identificar. Como conseqüência, maior sensibilidade implica caracterizar drogas que foram administradas ao atleta muito antes do controle. Essa maior sensibilidade faz com que a prática de interromper o abuso de drogas antes das competições fique cada vez mais arriscada para o atleta. É, portanto, fator importante na prevenção à prática do doping.

Após isolada e concentrada, a fração que contém os analitos, em geral, sofre uma derivatização, isto é, a transformação dos analitos pela reação com certas moléculas (agentes derivatizantes), em moléculas de maior volatilidade, inércia química e estabilidade térmica. Assim, os derivados podem facilmente e de modo reprodutível, sem perdas ou modificação, ser introduzidos no equipamento de análise $^{6,9}$. Para as substâncias dos quadros 5 a 10 e 14 a 16, a técnica empregada é a da cromatografia gasosa de alta resolução acoplada à espectrometria de massas (CG-EM). No 
caso dos estimulantes (quadro 6) faz-se uma triagem por CG com detector de nitrogênio e confirmam-se casos suspeitos por CG-EM. Eritropoetina (EPO) é analisada por eletroforese, distinguindo-se a sintética da endógena. Hormônios de crescimento (hGH), gonadotrofina coriônica humana (hCG), hormônio luteinizante (LH) e outros hormônios peptídicos são analisados por imunoensaio.

Para evitar situações polêmicas e empregando a máxima de "na dúvida, pró-réu", o COI definiu limites máximos permitidos para certas drogas cuja presença no organismo do atleta poderia advir de contaminação (alimentar, ambiental ou por fármacos permitidos com restrições; quadro 17). Isso aumenta a sofisticação e complexidade da análise, pois não basta identificar o analito, é necessário quantificá-lo dentro da precisão e exatidão adequadas.

\section{SISTEMA DE CONTROLE DE DOPAGEM}

Além da capacidade analítica, o laboratório deve apresentar sistema de gestão que garanta a qualidade de seus resultados. A avaliação do desempenho das operações e equipamentos é uma constante, garantindo que todos os passos do tratamento das amostras tenham sido realizados sem erro. Isso resulta num sistema complexo de garantia da qualidade. Esse sistema também envolve a chamada custódia da amostra e rastreabilidade das análises e documentos. Assim, é necessário controlar os responsáveis por cada

\section{QUADRO 17}

Concentrações máximas permitidas para certas drogas e sua justificativa (regulamentação do COI para 2001) ${ }^{16}$

\begin{tabular}{|c|c|c|}
\hline Substância & $\begin{array}{l}\text { Valor máximo } \\
\text { permitido pelo Col }\end{array}$ & $\begin{array}{l}\text { Motivo } \\
\text { do limite }\end{array}$ \\
\hline Cafeína & $12 \mu \mathrm{g} / \mathrm{ml}$ & Bebidas \\
\hline Carboxi-THC & $15 \mathrm{ng} / \mathrm{ml}$ & $\begin{array}{l}\text { Fumo } \\
\text { ambiental de } \\
\text { maconha }\end{array}$ \\
\hline Catina & $5 \mu \mathrm{g} / \mathrm{ml}$ & Medicamento \\
\hline Efedrina & $10 \mu \mathrm{g} / \mathrm{ml}$ & Medicamento \\
\hline Metilefedrina & $10 \mu \mathrm{g} / \mathrm{ml}$ & Medicamento \\
\hline Fenilpropanolamina & $25 \mu \mathrm{g} / \mathrm{ml}$ & Medicamento \\
\hline Pseudoefedrina & $25 \mu \mathrm{g} / \mathrm{ml}$ & Medicamento \\
\hline Morfina & $1 \mu \mathrm{g} / \mathrm{ml}$ & Alimento \\
\hline 19-norandrosterona & $\begin{array}{l}2 \mathrm{ng} / \mathrm{ml} \text { (homens); } \\
5 \mathrm{ng} / \mathrm{ml} \text { (mulheres) }\end{array}$ & Endógena \\
\hline Salbutamol & $\begin{array}{l}100 \mathrm{ng} / \mathrm{ml} \text { (estimulante); } \\
1.000 \mathrm{ng} / \mathrm{ml} \text { (anabólico) }\end{array}$ & Medicamento \\
\hline $\mathrm{T} / \mathrm{E}$ & $\begin{array}{c}6 \text { e/ou epitestosterona } \\
>200 \mathrm{ng} / \mathrm{ml}\end{array}$ & Endógenos \\
\hline
\end{tabular}

THC, tetraidrocanabinol; T, testosterona; E, epitestosterona.

Rev Bras Med Esporte - Vol. 7, № 4 - J ul/ Ago, 2001 manipulação e por cada documento recebido, gerado, ou enviado pelo laboratório. É necessário demonstrar que as análises sempre fornecerão resultados confiáveis e que toda a instrumentação foi calibrada frente a padrões internacionalmente aceitos. É imprescindível garantir o correto arquivamento e pronto acesso a toda documentação, seja ela administrativa ou resultante do processo de análise das amostras. E, como se não bastasse, é preciso submeter-se regularmente à auditoria por órgãos certificadores. No caso do controle de dopagem, o Comitê Olímpico Internacional (credenciamento pelo COI), o Inmetro (credenciamento pelas normas ISO-9000 e ISO-17025), bem como os próprios clientes.

O sistema de controle deve contar ainda com uma equipe de coleta treinada para essa finalidade. Para garantir a qualidade da coleta e coibir fraudes, em geral essas equipes são formadas por médicos com especialização em medicina do esporte, farmacêuticos, bioquímicos, etc. A sofisticação das fraudes na coleta e transporte das amostras para o laboratório fez com que o COI desenvolvesse um sistema à prova de fraudes. A começar pela coleta, que é feita pelo atleta urinando na presença do observador responsável por ela, com corante azul na água do vaso sanitário. O próprio atleta transfere a urina para dois frascos (prova e contraprova), que são por ele selados com tampas dotadas de lacre que se rompe ao abrir. O material de coleta e os frascos são escolhidos pelo atleta dentre vários disponíveis. Cada par de frascos tem numeração única, com o frasco da prova sendo o "A" e o da contraprova sendo o "B". Dependendo da sofisticação da Federação, selos podem ser adicionados aos frascos; os mesmos podem ser embalados em bolsas lacradas e estas ser acondicionadas em sacolas lacradas. Toda essa cadeia de identificação e lacres numerados é conferida quando a amostra é recebida no laboratório, ou aberta. O laboratório só identifica a amostra pelo seu número de código, não tendo nenhuma informação sobre a identidade do atleta. A chave para essa identificação fica retida em envelope lacrado e selado, guardado com o responsável pelo controle de dopagem junto à Federação solicitante. $\mathrm{O}$ número de código da Federação é lançado em caderno de registro do laboratório e, a partir daí, a amostra recebe um número de código do laboratório, com o qual passa por todos os procedimentos necessários à caracterização dos analitos.

Em geral coletam-se duas amostras de cada equipe, uma vez selecionados os atletas por sorteio. Esportes individuais em geral envolvem amostragem dos primeiros colocados e sorteio de alguns dos demais participantes. Há Federações que realizam amostragens "fora de competição" para, de forma mais eficaz, coibir a prática de interrupção do abuso de drogas antes das competições. 
Em caso de caracterização de analito proibido, comunica-se ao responsável pelo controle de dopagem junto à Federação, que toma as providências necessárias. A análise da contraprova é efetuada se solicitada pelo atleta, para confirmar na sua presença a caracterização da droga detectada nesta sua urina. Algumas das atividades envolvidas são apresentadas nos quadros 18 e 19.

\section{O CONTROLE DE DOPAGEM NO BRASIL DE ACORDO COM A METODOLOGIA PRECONIZADA PELO COMITÊ OLÍMPICO INTERNACIONAL (COI)}

O controle de dopagem foi iniciado em 1989, com metodologia do COI, quando o Ladetec-IQ/UFRJ contou com o apoio decisivo da CBF e do Dr. Eduardo H. De Rose, da Comissão Médica do Comitê Olímpico Internacional, para realizar o controle anti-doping da Copa América de Futebol de 1989. No início de 1989, os coordenadores do Ladetec foram treinados no Cologne Workshop in Dope Analysis ${ }^{16}$ realizado no, então, laboratório central de controle de dopagem do COI, em Colônia, na Alemanha. Para o antidoping da Copa América, o Ladetec contou com a colaboração do Laboratório Olímpico de Barcelona, que deslo-

\section{QUADRO 18}

Complexidade da análise para o controle de dopagem no esporte

Manutenção, atualização e aperfeiçoamento de equipamentos; aquisição de novos equipamentos.

Aquisição de padrões, reagentes, peças, solventes, derivatizantes, cartuchos, septos, gases, vidraria, etc.

Atualização e validação de metodologia, geração de urinas positivas, testes intralaboratoriais e interlaboratoriais, arquivamento de dados.

Arquivamento de amostras em condições frigorificadas a $-18^{\circ} \mathrm{C}$

Arquivamento de documentação por até dez anos.

Pesquisas de novas drogas, testes de excreção, atualização bibliográfica.

Pagamento e treinamento continuado de pessoal, participação em congressos e workshops.

Realização das quatro a sete triagens para cada amostra.

Administração, contabilidade, sistema da qualidade, testes de credenciamento.

Participação em campanhas de divulgação, como especialistas em julgamentos, como consultores em recursos contra punições.

Credenciamento ISO 17025 e ISO 9000.

Credenciamento pelo Comitê Olímpico Internacional (COI). cou o Dr. Rafael de La Torre para a UFRJ. Ele ajudou a organizar o laboratório, treinar o pessoal envolvido e estabelecer as rotinas de análise.

Foi fundado, então, o LAB DOP, provisoriamente, nas próprias instalações do Ladetec.

Ainda em 1989, o Ministério da Agricultura solicitou a participação do Ladetec no PNCRBC (Programa Nacional de Controle de Resíduos Biológicos em Carnes), a qual prossegue até hoje.

Simultaneamente, a Confederação Brasileira de Voleibol (CBV) contratou o controle anti-doping, para o Campeonato Mundial de Voleibol Masculino de 1990.

Desde então, foram atendidas mais de 40 Federações Desportivas nacionais e internacionais, empregando sempre a metodologia de referência do Comitê Olímpico Internacional (COI).

Sob credenciamento temporário do COI foi realizado no LAB DOP o anti-doping do Mundial de Clubes da FIFA e o do pré-olímpico de futebol em janeiro e fevereiro de 2000.

\section{QUADRO 19}

Complexidade da coleta para o controle de dopagem

Kits de coleta envolvendo materiais descartáveis e recicláveis.

Bebidas para os atletas se hidratarem.

Diária da equipe médica de alto nível disponível do início do jogo até o término da coleta (demora usual pela dificuldade do atleta, desidratado e inibido, em urinar); oito a $12 \mathrm{~h}$ de trabalho, geralmente à noite ou finais de semana.

Transporte do material para os locais de coleta.

Transporte das amostras para o laboratório.

Formulários, fichas e documentação de controle.

Revisão e impressão de regulamentos.

Administração, comunicação e arquivamento.

Manutenção de uma comissão de controle de dopagem de alto nível.

Realização de contraprovas, com deslocamento da comissão para o laboratório, com perda de pelo menos um dia de trabalho de todos os seus membros.

Assistência aos órgãos de justiça desportiva.

Gestão das equipes de coleta envolvendo todo o território nacional, com treinamento continuado das equipes, sua manutenção com uniformes, crachás de identificação e material auxiliar de coleta.

Contatos com dirigentes e médicos dos times e clubes envolvidos nos campeonatos.

Contatos com o laboratório e atualização nas práticas de dopagem e seu controle.

Atualização dos procedimentos e materiais de coleta.

Credenciamento pela ISO 9000 . 
Outra área importante de atuação do LAB DOP é a análise de quimioterápicos e de apoio à clínica médica, como ilustrado, por exemplo, pelos convênios firmados com o Instituto Nacional do Câncer (INCa/RJ) e com o Instituto Nacional de Qualidade em Saúde (INCQS/Fiocruz), além do diagnóstico precoce de erros inatos do metabolismo em recém-nascidos. Assim fica demonstrado que o controle anti-doping pode ser considerado como um dos aspectos da química aplicada à medicina, devendo ser incentivada a participação dos laboratórios de controle em pesquisas e diagnósticos de interesse médico.

Cumpre reconhecer o apoio político fornecido pelos então secretários de Esportes da Presidência da República, Srs. Arthur Antunes Coimbra, o Zico, e Bernard Rajzman, o que muito contribuiu para a conscientização do governo e da própria Universidade, para a importância do controle de dopagem no esporte.

O LAB DOP hoje já opera em instalações próprias, compatíveis com as exigências do COI, atendendo mais de 40 Federações/Confederações esportivas.

O laboratório envolve o trabalho de mais de 40 pessoas entre funcionários, pesquisadores, técnicos, alunos de pósgraduação e de iniciação científica que se revezam na evolução da capacitação da Universidade na área de química analítica orgânica.

A UFRJ é a única instituição do país credenciada para os exames anti-doping que dispõe de um aparato técnico de alta tecnologia e pessoal treinado para atender as rigorosas exigências do COI.

Buscando capacitação para atender a demanda de grandes eventos, o Instituto de Química da UFRJ, através do LAB DOP/Ladetec, enviou seus técnicos para trabalharem nas Olimpíadas de Barcelona (1992) e Atlanta (1996) e Pan-Americano do Canadá (1999), a convite do COI e da Odepa.

O LAB DOP-Laboratório de Controle de Dopagem também realizou o exame prévio de controle de dopagem da delegação brasileira em Atlanta, enviando técnicos do laboratório para os EUA. Para as Olimpíadas de Sydney o LAB DOP foi contratado pelo COB para avaliar toda a equipe olímpica e paraolímpica brasileiras, realizando todas as análises em suas próprias instalações.

O LAB DOP/Ladetec está credenciado pelo Comitê Olímpico Internacional e pelo Inmetro.

O controle de dopagem é uma parte integrante das atividades do Ladetec que, desde 1984, vem realizando serviços de pesquisa e desenvolvimento, envolvendo cromatografia gasosa de alta resolução e espectrometria de massas, para indústrias e centros de pesquisas.
O controle de dopagem exercido pelo LAB DOP no Brasil envolve a análise de mais de 2.500 amostras por ano e o índice de positivos se situa na faixa de $1 \%$. Como $95 \%$ das amostras analisadas provêm do futebol e vôlei, essa percentagem baixa de positivos compara-se à situação internacional. Tradicionalmente, esses dois esportes têm menos casos de doping devido às suas características. Os laboratórios credenciados pelo COI, trabalhando com um universo maior de modalidades esportivas (em especial, natação, musculação, levantamento de peso), apresentam de 1,5 a $2,5 \%$ de casos positivos.

$\mathrm{O}$ espectro de drogas de abuso é ainda mais amplo ${ }^{19} \mathrm{e} \mathrm{o}$ controle de dopagem no esporte é apenas uma das diversas iniciativas necessárias à prevenção dessa prática na sociedade contemporânea.

\section{AGRADECIMENTOS}

Ao Dr. Eduardo H. De Rose, pela confiança e contínuo apoio a nossas atividades. À CBF, na pessoa do Dr. Marco Antonio Teixeira, pela confiança e apoio financeiro, além da determinação de universalizar o controle de dopagem executado no Brasil. Aos componentes do Ladetec, cuja dedicação, determinação e excelência permitiram, em dez anos, criar um laboratório de nível olímpico na América Latina. Ao IQ-UFRJ, que entendeu a importância da pesquisa útil, de impacto socioeconômico, como uma das atribuições da verdadeira Universidade.

\section{REFERÊNCIAS}

1. Australian Sports Drug Agency, ASDA. Drugs in sport. http://www.asda. org.au/drugsin.html.2000.

2. De la Torre R. Specific agents. In: Karch SB, editor. Drug abuse handbook. Boca Raton: CRC Press, 1998:648-52.

3. Hoberman JM, Yesalis CE. The history of synthetic testosterone. Sci Am 1995:60-5.

4. Dickman S. East Germany: science in the disservice of the state. Science 1991;254:26-7.

5. Catlin DH, Kammerer RC, Hatton CK, Sekera MH, Merdink JL. Analytical chemistry at the Games of the XXIIIrd Olympiad in Los Angeles, 1984. Clin Chem 1987;33:319-27.

6. Schänzer W. Detection of exogenous anabolic androgenic steroids. In: Karch SB, editors. Drug abuse handbook. Boca Raton: CRC Press, 1998: 671-89.

7. Laranjeira R. Entrevista sobre a descriminalização da maconha. Ciência Hoje 2000:27:6-10.

8. Segura J. Doping control in sports medicine. Ther Drug Monit 1996;18:471-6.

9. Solans A, Carnicero M, de la Torre R, Segura J. Comprehensive screening procedure for detection of stimulants, narcotics, adrenergic drugs, and their metabolites in human urine. J Anal Toxicol 1995;19:104-14.

10. Barturen F, Meana JJ, Bizkaia L, editors. Drogas y deporte: farmacologia del doping. Avances en farmacología de drogadependencias. Bilbao, Universidade de Deusto, 1995.

11. International Olympic Committee. Guide du controle antidopage des Jeux Olympiques de Sydney 2000. Lausanne, COI, 2000. 
12. Karch SB, editor. Drug abuse handbook. Boca Raton: CRC Press, 1998.

13. Confederação Brasileira de Futebol. Regulamento de controle de dopagem. Rio de Janeiro: CBF, 2000. (atualizado anualmente)

14. Amorim R. Dose para cavalo. Onda de produtos para animais mata lutador de jiu-jitsu no Rio de Janeiro. Veja 2000;(9 de agosto):78-9.

15. Ritter SK. Faster, higher, stronger: nutritional supplements, anabolic steroid precursors, peptide hormones tempt athletes to embrace performance enhancement. Chem Eng News 1999:42-52.

16. Anais dos "Cologne Workshop in dope analysis" editados anualmente pela Strauss Pub, Colônia.

17. Henderson GL, Harkey MR, Zhou C, Jones RT, Jacob III P. Incorporation of isotopically labeled cocaine and metabolites into human hair: 1. Dose-response relationships. J Anal Toxicol 1996;20:1-12.

18. Van Ginkel LA. Immunoaffinity chromatography, its applicability and limitations in multi-residue analysis of anabolizing and doping agents. $\mathbf{J}$ Chromatogr 1991;564:363-84.

19. Comité Français d'Education pour la Santé. Drogues: savoir plus risquer moins. Paris: EURO RSCG publishing: 2000.

Comitê Olímpico Internacional, COI. www.olympic.org.

20. Lukas SE. CNS effects and abuse of anabolic-androgenic steroids. Annu Rev Pharmacol Toxicol 1996:333-57.

21. Zurer PS. Drugs in sports. Chem Eng News 1984:62:69-78.

22. Zurer PS. SmithKline Beecham's Atlanta lab gears up for Olympic drug testing. Chem Eng News 1996:28-9.
23. Park J, Songia P, Lho D, Choo HP, Chung B, Ion C, Min H, Choi MJ. Drug testing at the $10^{\text {th }}$ Asian games and $24^{\text {th }}$ Seoul Olympic games. J Anal Toxicol 1990;14:66-72.

24. De Rose EH, Nobrega ACL. Drogas lícitas e ilícitas. In: Ghorayeb N, Barros Neto TL. O exercício. São Paulo: Atheneu, 1999:395-405.

25. Feder MG, Cardoso JN, Marques MAS, De Rose EH. Informações sobre o uso de medicamentos no esporte. Rev Bras Med Esporte 2000;6: 125-30.

26. De la Torre R. Fármacos beta-adrenérgicos, estructura química y actividad farmacológica. In: Barturen F, Meana JJ. Drogas y deporte: farmacología del doping. Bilbao: Universidade de Deusto: 65-72.

27. Catlin DH. Anabolic androgenic steroids. In: Karch SB, editor. Drug abuse handbook. Boca Raton: CRC Press, 1998:653-71.

28. Laidler P, Cowan DA, Hider RC, Kicman AT. New decision limits and quality-control material for detecting human chorionic gonadotropin misuse in sports. Clin Chem 1994;40:1306-11.

29. Ekblom B. Erythropoietin. In: Karch SB, editor. Drug abuse handbook. Boca Raton: CRC Press, 1998:710-20.

30. Birkeland KI. Transfusiones sanguíneas y empleo de eritropoyetina en el deporte: por qué se usan, cómo funcionam y cómo pueden ser detectados. In: Barturen F, Meana JJ. Drogas y deporte: farmacología del doping. Bilbao: Universidade de Deusto:97-111.

31. Cuneo RC, Wallace JD, Sönken P. Growth hormone abuse in elite athletes. In: Karch SB, editor. Drug abuse handbook. Boca Raton: CRC Press, 1998:690-710.

32. Reynolds JEF, editor. Martindale. The extra pharmacopoeia. London: The Pharmaceutical Press, 1993. 